\title{
PRINCÍPIOS E NORMAS GERAIS LICITATÓRIAS
}

\section{DIOGENES GASPARINI*}

I. - INTRODUÇÃO. Andou bem o e. Tribunal de Contas do Município de São Paulo, ao colocar na abertura do II Seminário de Direito Administrativo - Licitação e Contrato - Direito Aplicado, a palestra Princípios e Normas Gerais. Com efeito, ao serem oferecidas as noções a respeito desses dois importantes institutos do Direito e especialmente no campo das licitações e contratos, restou facilitada a exposição e a compreensão das palestras que se seguiriam, permeadas, certamente, por referências e mesmo por discussões envolvendo sua adequada utilização. Essa preliminar abordagem ajudaria na compreensão dos demais assuntos. Neste retrospecto de nossa palestra estão as idéias então expostas, de sorte que trataremos primeiro dos princípios e em seguida as normas gerais. Assim:

II. - PRINCÍPIOS. Todas as ciências são dotadas de princípios. Assim é na filosofia, na matemática, na física e no direito, ainda que tenham outros nomes, como axiomas, postulados ou dogmas. São proposições fundamentais de um sistema. "Os princípios", segundo ensina Carlos Ari Sundfeld (Fundamentos de direito público. São Paulo, Malheiros, 1992, p. 18), "são as idéias centrais de um sistema, ao qual dão sentido lógico, harmonioso, racional, permitindo a compreensão de seu modo de organizar-se".

Aclara sua lição tomando certa unidade militar como exemplo de sistema, composta de soldados, suboficiais e oficiais. Com facilidade, diz Carlos Ari Sundfeld, descobrimos a idéia geral que explica seu funcionamento: "os subordinados devem cumprir as determinações dos superiores". De nada adiantaria conhecer as várias categorias de militares, suas atividades, os veículos que utilizam em suas manobras e outros aspectos particulares dessa unidade militar se não tivermos pleno conhecimento do princípio que organiza todos esses elementos: o princípio da hierarquia. Assim, para conhecer um sistema, qualquer que seja, precisamos conhecer seus princípios.

* Advogado. Mestre e Doutor pela PUC-SP. Professor da Escola Superior de Direito Constitucional - SP. Ex-Professor Titular e Professor Honoris Causa da Faculdade de Direito de São Bernardo do Campo - SP.

R. Dir. Adm.,

Rio de Janeiro, 239: 119-125,

Jan./Mar. 2005 
III. - PRINCÍPIOS JURÍDICOS. O direito é um sistema e para conhecê-lo e aplicá-lo precisamos identificar seus princípios, tanto quanto precisamos dessas proposições para diferenciá-lo de outras ciências e para distinguir seus dois grandes compartimentos: Direito Público e Direito Privado. Aquele marcado pelos princípios da legalidade e do interesse público, enquanto este gizado pelos princípios da autonomia da vontade e do interesse privado. Essas proposições são os princípios jurídicos. Mas não é só nisso que está a importância dos princípios jurídicos, pois devem ser tomados para a solução de problemas jurídicos concretos, assevera Carlos Ari Sundfeld (Licitação e contrato administrativo. São Paulo, Malheiros, 1994, p. 19) e para a colmatação do Direito.

CONCEITO. Enfim, o que é princípio jurídico? De forma bem simples podemos afirmar que é uma proposição, uma frase de conteúdo jurídico e de importância fundamental para a compreensão e aplicação do Direito ou de seus institutos, como é a licitação. Quem em algum momento da vida não ouviu certas frases, sem se aperceber de que estava frente a um princípio jurídico: quem pode o mais pode o menos; o assessório segue o principal; quem quer os fins deve dar os meios, ninguém pode dar mais do que tem; os serviços públicos são contínuos e todos são iguais perante a lei? Todos se preordenam à aplicação do Direito. São, portanto, regras jurídicas, ainda que não sejam postas pelo legislador.

Resta, então, evidente que devem ser levadas em conta na solução dos problemas legais do dia-a-dia, até em detrimento das normas legais comuns, pois estas devemlhe atenção, obediência. A preocupação de oferecer uma perfeita conceituação do que sejam os princípios jurídicos, nos leva às lições de Celso Antônio Bandeira de Mello (Curso de direito administrativo, $16^{\mathrm{a}}$ ed.. São Paulo, Malheiros. 2003, p. 817) que, melhor do que ninguém. os tem estudado dentro do Direito Administrativo. Vale, pois transcrever suas ensinanças: "Princípio - já averbamos alhures - é, por definição, mandamento nuclear de um sistema, verdadeiro alicerce dele, disposição fundamental que se irradia sobre diferentes normas compondo-lhes $\rho$ espírito e servindo de critério para sua exata compreensão e inteligência exatamente por definir a lógica e a racionalidade do sistema normativo, no que lhe confere a tônica e dá sentido harmonioso."

PARTE DO ORDENAMENTO JURÍDICO. Sendo regras jurídicas, os princípios, tanto quanto as normas, integram o ordenamento jurídico, conjunto de prescrições impostas coativamente pelo Estado. Assim, no ordenamento convivem harmoniosamente as normas e os princípios jurídicos. $\mathrm{O}$ art. $8^{\circ}$ da Lei federal das Licitações prescreve que "A execução das obras e dos serviços deve programar-se, sempre, em sua totalidade, previstos seus custos atual - e final e considerados os prazos de suas execução", é, assim, norma legal, enquanto a obrigatoriedade de "selecionar a proposta mais vantajosa para a Administração", constante do art. $3^{\circ}$ dessa lei, é princípio jurídico. Portanto, não se pode contratar a execução de uma obra senão pela proposta mais vantajosa para a Administração Pública.

As normas sempre estão explicitadas no ordenamento jurídico, de sorte que não há norma legal válida implícita ou fora do sistema jurídico. Com os princípios não 
ocorre o mesmo, pois a maioria deles não está expressamente grafada no ordenamento jurídico, mas mesmo assim válidos, pois são deduzidos da Constituição. Outros, no entanto, estão expressamente colocados no ordenamento jurídico, como são exemplos os princípios da "dignidade pessoa humana" (art. $1^{\circ}$, III, da CF) e da igualdade de todos perante a lei (art. $5^{\circ}$ da $\mathrm{CF}$ ). Por ser assim, é natural a dificuldade para sua identificação e determinação da amplitude de sua aplicação.

IMPORTÂNCIA. Sua importância é evidente na medida em que é "disposição fundamental que se irradia sobre diferentes normas compondo-lhes o espírito e servindo de critério para sua exata compreensão e inteligência exatamente por definir a lógica e a racionalidade do sistema normativo, no que lhe confere a tônica e dá sentido harmonioso". De sorte que, sua violação repercute mais gravemente no sistema que o desrespeito à norma. O porque dessa afirmação está no preciso magistério de Celso Antônio Bandeira de Mello (ob. cit., p. 818), pois assevera que "A desatenção ao princípio implica ofensa não apenas a um específico mandamento obrigatório, mas a todo o sistema de comandos. É a mais grave forma de ilegalidade ou inconstitucionalidade, conforme o escalão do princípio atingido, porque representa insurgência contra todo o sistema, subversão de seus valores fundamentais, contumélia irremissível a seu arcabouço lógico e corrosão de sua estrutura mestra". Decorre daí sua superioridade em relação as normas positivadas, inclusive as gerais. Com efeito, acentua, nesse particular, Carlos Ari Sundfeld (Fundamentos cif., p. 140) que "O princípio jurídico é norma de hierarquia superior à das regras, pois determina o sentido e o alcance destas, que não podem contrariá-lo, sob pena deporem risco a globalidade do ordenamento jurídico. Deve haver coerência entre os princípios e as regras, no sentido de que vai daqueles para estas."

FUNÇÕES. Além da relevância já referida, os princípios cumprem, segundo as lições de Carlos Ari Sundfeld (Fundamentos cif., p. 141), duas importantes funções: determinam a adequada interpretação das regras e permitem a colmatação de suas lacunas. Quanto a interpretação das normas legais, esse autor registra as seguintes regras: “a) É incorreta à interpretação da regra, quando dela derivar contradição, explicita ou velada, com os princípios; b) Quando a regra admitir logicamente mais de uma interpretação, prevalece a que melhor se afinar com os princípios; c) Quando a regra tiver sido redigida de modo tal que resulte mais extensa ou mais restrita que o princípio, justifica-se a interpretação extensiva ou restritiva, respectivamente, para calibrar o alcance da regra com o princípio". Já para a lacuna do ordenamento jurídico quanto a específico caso, diz esse autor (Fundamentos cit., p. 142) "que a regra faltante deve ser construída de modo a realizar concretamente a solução indicada pelos princípios", que não é outra coisa senão a aplicação do art. $4^{\circ}$ da Lei de Introdução ao Código Civil.

PRINCÍPIOS DO ORDENAMENTO JURÍDICO. Os princípios jurídicos, nem sempre contam com seus respectivos conteúdos indicados expressamente no ordenamento jurídico. Pode-se dizer que os princípios jurídicos não são legislados, produzidos legislativamente, como são as normas legais, a lei. É comum encontrar 
seus nomes na Constituição e nas leis. Aqueles são princípios constitucionais e disso são exemplos os princípios da legalidade, impessoalidade, moralidade, publicidade e eficiência, cujo regime de cada um é dado pela doutrina. Este são princípios legais e exemplos deles encontram-se no art. $3^{\circ}$, da Lei Federal das Licitações e Contratos da Administração Pública, alguns específicos da licitação, enquanto outros aplicáveis à Administração Pública no comum de suas atividades e comportamentos. Por essa regra, a licitação será processada e julgada na estrita conformidade dos princípios básicos da legalidade, da impessoalidade, da moralidade, da igualdade, da publicidade, da probidade administrativa, da vinculação ao instrumento convocatório, do julgamento objetivo e dos que lhe são correlates e entre entes está o princípio da competitividade. $\mathrm{O}$ conteúdo ou o regime de cada um é dado pela doutrina.

AMPLITUDE NA APLICAÇÃO. Alguns princípios têm maior largueza do que outros na sua aplicação e por essa razão são classificados em onivalentes, plurivalentes e monovalentes, dividindo-se estes últimos em gerais e específicos. Onivalentes são os que valem para qualquer ciência, como é o princípio da não-contradição. Plurivalentes são os que valem para um grupo de ciências, a exemplo do princípio da causalidade em relação às ciências naturais. Monovalentes são os que só valem para uma ciência, como é o princípio da legalidade, só aplicável ao Direito. Monovalentes gerais são os princípios que valem para um só ramo de certa ciência, como é o princípio do interesse público que somente se aplica ao Direito Público. Monovalentes específicos são os princípios que valem unicamente para uma parte de um ramo de determinada ciência, como é o caso do princípio da continuidade do serviço público que só vale para o Direito Administrativo.

PRINCÍPIOS DA LICITAÇĀO. Os princípios da licitação conforme a classificação antes referida são monovalentes específicos, pois sua aplicação cinge-se aos certames licitatórios e outros procedimentos que, em tese, selecionam o melhor, seja uma proposta para um negócio de interesse da Administração Pública ou uma pessoa para ingresso no serviço publico. A doutrina costuma indicar, além dos princípios monovalentes gerais, como são os da legalidade, da publicidade, do interesse público, e da igualdade, os que lhe são específicos. Desses são exemplos os princípios da vinculação ao instrumento convocatório, do julgamento objetivo, da competitividade, da adjudicação compulsória. A esses princípios, nada diferentes dos demais, é aplicável o regime jurídico que tecemos à generalidade dos princípios jurídicos.

IV - NORMAS GERAIS. Já vimos que os princípios convivem com as normas ou regras do sistema jurídico, inclusive com as denominadas normas gerais. Esta convivência, ademais, é no sentido da prevalência dos princípios sobre as normas gerais. O fato de serem normas gerais não as retira dessa subserviência jurídica aos princípios.

NATUREZA JURÍDICA. As normas gerais são leis ordinárias federais, não exigindo para sua edição qualquer quorum ou procedimento especial de aprovação. São enquadradas no art. 59, III, da Constituição Federal. Embora seja assim devemos 
reconhecer-lhe que não são apenas leis federais, mas nacionais. "Esse tema", assevera Adilson Abreu Dallari (Aspectos jurídicos da licitação, $4^{a}$ ed., São Paulo, Saraiva, 1997, p. 21), "foi bastante desenvolvido por Geraldo Ataliba, que a ele agregou uma importantíssima distinção entre leis nacionais e leis federais, ao afirmar que as normas gerais são, 'por definição e pela sistemática constitucional, leis nacionais; leis que não se circunscrevem ao âmbito de qualquer pessoa política, mas que os transcendem aos três."

COMPETÊNCIA. A competência para editar normas gerais é exclusiva da União, quando se tratar de matéria concorrente (art. 24, da CF) ou onde for especificamente indicado no Texto Maior, como é o caso das Licitações e Contratos (art. 22, XXVII, da CF). Aos Estados e ao Distrito Federal não se reconhece igual atribuição, mas se thes reserva a atribuição de editar normas suplementares (art. 24, $\S 2^{\circ}$, da CF), editadas, portando, no vazio deixado obrigatoriamente pela norma geral. Essas normas suplementares, advirta-se, não se confundem com a complementares, mencionadas no art. 59, II, que exigem para sua aprovação, nos termos do art. 69, maioria absoluta de votos favoráveis. Embora seja assim, cabe alertar que na ausência de lei sobre normas gerais, a competência dos Estados e do Distrito Federal é plena, atribuição que mesmo em tais casos não se reconhece em favor dos Municípios. Com o advento das normas gerais suspende-se a eficácia da lei estadual no que the for contrário (art. $24, \S 4^{\circ}$, da CF).

CONCEITO. É muito penoso conceituar com a desejada precisão lógica e jurídica o que seja norma geral. Também não há conceito legal dessa espécie normativa. Encontram-se apenas referências a elas na Constituição Federal, como é o caso do art. 22, XXVII, que atribui à União a competência para editar normas gerais sobre licitação e contratação. Também há referências nas leis, a exemplo do Diploma Federal Licitatório que em seu art. $1^{\circ}$ diz que essa lei estabelece normas gerais sobre licitações e contratos administrativos. Conceito de norma geral em sentido amplo é dado por Carlos Pinto Coelho Motta (Eficácia nas licitações e contratos, $9^{\mathrm{a}}$ ed., Belo Horizonte, Del Rey, 2002, p. 87), calcado nas lições de Alice Gonzalez Borges.

De fato, nessa passagem de sua preciosa monografia define normas gerais como “aquelas que, por alguma razão, convém ao interesse público sejam tratadas por igual, entre todas as ordens da Federação, para que sejam devidamente instrumentalizados e viabilizados os princípios constitucionais com que têm pertinência". Dada a mencionada dificuldade, é mais fácil dizer o que não é norma geral do que conceituá-la. Com efeito, assevera Adilson Abreu Dallari (ob. cit., p. 20) que "é mais fácil chegar à norma geral pelo caminho inverso, dizendo o que não é norma geral. Não é norma geral aquela que corresponde a uma especificação, a um detalhamento". Nessa linha não é norma geral a que dispõe sobre o assunto exaustivamente.

CARACTERÍSTICA. É característica da norma geral dispor de modo uniforme para todos os entes da federação, daí as críticas que lhe atiram, pois nos muitos 
brasis que temos essa uniformidade dificulta a atividade administrativa, que tem que contratar valendo-se de regras próprias para as grandes Administrações Públicas. Outra característica é ser nacional federal.

V. - NORMAS GERAIS SOBRE LICITAÇÃO. As normas gerais sobre licitação e contratação não diferem, nem poderiam, desse regime geral sumulado, salvo no que respeita à matéria: licitação e contratos administrativos. São encontráveis na Lei federal das Licitações e Contratos da Administração Federal. Embora voltadas especificamente para uma modalidade licitạtória, também são identificáveis na Lei Federal $n^{\circ} 10.520$, de 2002, conhecida como Lei Federal do Pregão.

CONCEITO. Por terem por objeto as matérias licitação e contratos administrativos, são definidas levando em conta essa peculiaridade. Jessé Torres Pereira Júnior (Comentários à lei das licitações e contratações da Administração Pública, $5^{\mathrm{a}}$ ed.. Rio de Janeiro, Renovar, 2002, p. 19) as conceitua como "toda disposição da Lei no 8.666/93 que se mostre indispensável para implementar os princípios constitucionais reitores da Administração Pública e os básicos arrolados em seu art. $3^{\circ}$ ”.

IDENTIFICAÇĀO. Se definir as normas demanda enorme trabalho, identificálas entre todas as normas de certa lei revela-se labor ainda maior. É o que ocorre com a Lei Federal das Licitações e Contratos da Administração Pública. De fato, dispõe seu art. $1^{\circ}$, que "Esta Lei estabelece normas gerais sobre licitações e contratos administrativos...". Essa diç̧̃ão, entendida como sendo todas as disposições dessa lei, normas gerais, seria inconstitucional, pois afrontaria a autonomia dos entes federados em matéria administrativa. Melhor, então, seria entendê-la como criadora de normas gerais e especiais, pois cabe à União editar essas duas modalidades de normas jurídicas. As gerais obrigatórias à todos os entes federados e as especiais obrigatórias somente à União. De sorte que, caberia ao intérprete desvendar as normas gerais contidas nessa lei, como fizeram alguns autores. Toshio Mukai (Direito administrativo sistematizado. São Paulo, Saraiva, 1999, p. 259) oferece completo e oportuno inventário das normas da Lei Federal das Licitações que considera normas gerais, enquanto Jessé Torres Pereira Júnior (ob. cit.) a cada dispositivo comentado diz o "caráter da norma", ou seja, se cuida ou não de norma geral e explica porque assim entende.

PRINCÍPIOS E NORMAS GERAIS. Nesta altura cabe mostrar que princípios jurídicos e normas gerais não se confundem, ainda que alguns autores as definam como aquelas que fixam princípios e diretrizes. Os princípios e as normas gerais têm específicas razões para existirem. Pode-se afirmar, para diferenciar os princípios das normas gerais, que: a) Os princípios são mandamentos nucleares de um sistema, que se irradiam sobre diferentes normas compondo-lhes o espírito e servindo de critério para sua exata compreensão e inteligência; as normas gerais, ao contrário, são regras subalternas destinadas a dar aplicabilidade uniforme aos princípios, b) Os princípios podem ser explícitos ou implícitos; as normas gerais são sempre explícitas, c) Os princípios podem estar na Constituição Federal e nas leis; as normas só podem 
estar nas leis, d) Os princípios prestam-se a conhecer o Direito e facilitar seu perfeito manuseio; as normas gerais prestam-se a solução das situações concretas sobre as quais incidem, e) Os princípios servem à colmatação do Direito; as normas gerais aceitam as lacumas, $\mathrm{f}$ ) Os princípios dirigem-se ao aplicador da lei; as normas gerais destinam aos casos concretos, g) Os princípios submetem todos, inclusive o legislador, aos seus termos; as normas gerais só os envolvidos no caso concreto. 
Temas de Direito Constitucional

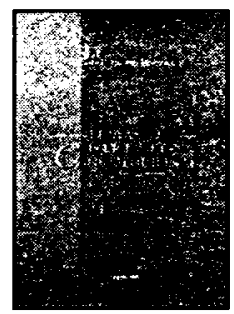

\section{Luis Roberto Barroso}

Ret. 0300

Encadernado

660 págs.

Form. $16 \times 23$

$2002 / 2^{\mathrm{ed}} \mathrm{ed}$

ISBN 85-7147-243-2

Reúne alguns dos melhores trabalhos do autor, nos quais são discutidos temas atuais como: segurança juríica; comissōes parlamentares de inquérito; controle de programação de TV; a crise da Federação; princípios constitucionais, razoabilidade e isonomia; liberdade de expressão e direito à informação; atuação econômica do Estado, espaço público e privado; aspectos do processo de impeachment, autonomia desportiva.

\section{Temas de Direito Constitucional - Tomo II}

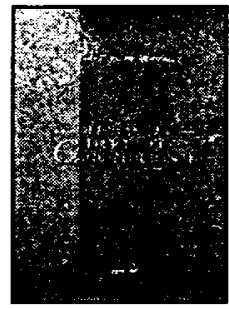

\section{Luis Roberto Barroso}

Ref. 0415

Encadernado

708 págs.

Form. $16 \times 23$

2003

ISBN 85-7147-308-0

A parte lé dedicada aos Artigos, nos quais prevalece 0 conteúdo doutrinário, a discussāo abstrata de princípios, conceitos e especulaçōes teóricas. Na Parte II estão reunidos os Pareceres, textos elaborados mediante solicitação e tendo por objeto questões concretas, cujo equacionamento exigia pesquisa e investigação de cunho acadêmico. E na Parte Ill encontram-se os Escritos - artigos publicados na imprensa, prefácios de livros nos quais se fez alguma reflexão doutrinária e um discurso de formatura.

\section{Temas de Direito Constitucional - Tomo III}

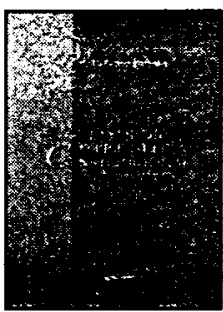

\section{Luis Roberto Barroso}

Ref. $X X X$

Encadernado

594 págs.

Form. $16 \times 23$

2005

ISBN $85-7147-X X X$

A exemplo dos anteriores, este volume reúne trabalhos acadêmicos, profissionais e jornalísticos que possam ter algum interesse para o público em geral.

\section{Teoria dos Direitos Fundamentais}

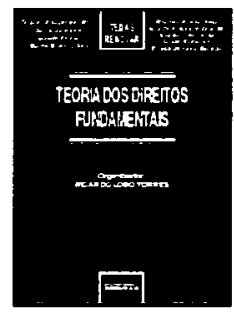

Ricardo Lobo Torres (org.)

Ref. 0219

Brochura

446 págs.

Form. $14 \times 21$

$2001 / 2^{\mathrm{a}} \mathrm{ed}$.

ISBN 85-7147-277-7

Esta coletânea de artigos e ensaios tem por objeto o estudo da fundamentação, da eficácia, da extensão e da interpretação dos direitos básicos, tanto no plano constitucional como no internacional. Os artigos transitam por temas de indubitável atualidade como o debate entre os liberais e os adeptos do comunitarismo, a cidadania multidimensional, a relaçāo entre a bioética e os direitos humanos e a análise da dicotomia público-privado em tace da questão da colisão dos princípios. 